\title{
Involvement of $\beta$ Adrenergic Receptors in Spasmolytic Effect of Caulerpine on Guinea Pig Ileum
}

Luiz Henrique Agra Cavalcante-Silva ${ }^{1}$, Ana Carolina de Carvalho Correia ${ }^{2}$, Jéssica Celestino Ferreira Sousa $^{3}$, José Maria Barbosa-Filho ${ }^{3,4}$, Bárbara Viviana de Oliveira Santos ${ }^{3,4}$, George Emmanuel C. de Miranda $^{5}$, Magna Suzana Alexandre-Moreira ${ }^{2}$ and Fabiana de Andrade Cavalcante ${ }^{3,6 *}$

${ }^{1}$ Biotechonology Center, Federal University of Paraíba, João Pessoa 58051-900, PB, Brazil

${ }^{2}$ Institute of Biological Sciences and Health, Federal University of Alagoas, Maceió 57020-720, AL, Brazil

${ }^{3}$ Postgraduate Program in Natural Products and Synthetic Bioactive, Federal University of Paraíba, João Pessoa 58051-900, PB, Brazil

${ }^{4}$ Department of Pharmaceutical Sciences, Federal University of Paraíba, João Pessoa 58051-900, PB, Brazil

${ }^{5}$ Department of Systematics and Ecology, Federal University of Paraíba, João Pessoa 58051-900, PB, Brazil;

${ }^{6}$ Department of Physiology and Pathology, Federal University of Paraíba, João Pessoa 58051-900, PB, Brazil

*Authors to whom correspondence should be addressed; E-Mails: fabianacavalcante@ltf.ufpb.br; Tel.: +55-833216-7126; Fax: +55-83-3216-7502.

\begin{abstract}
Previously, we demonstrated that caulerpine has spasmolytic effect on guinea pig ileum. The aim of this study was to investigate pathways of its spasmolytic action. We test caulerpine against phasic contractions induced by carbachol in the circular layer of guinea pig ileum and this alkaloid did not inhibit these contractions, indicating that caulerpine did not interfering with the mobilization of $\mathrm{Ca}^{2+}$ from intracellular stores. Additionally, the spasmolytic effect of caulerpine did not involve $\mathrm{K}^{+}$channels. Furthermore, we observed that $\alpha_{2}$-adrenergic receptors were not involved in the spasmolytic effect of caulerpine, since the relaxation curve induced by caulerpine was not shifted in the presence of yohimbine ( $\alpha_{2}$-adrenergic antagonist). However, in the presence of propranolol ( $\beta$-adrenergic antagonist), the relaxation curve induced by caulerpine was right-shifted, resulting in a fivefold increase in $\mathrm{EC}_{50}$. Thus, a possible mechanism for the spasmolytic action of caulerpine is the activation of $\beta$-adrenergic receptors.
\end{abstract}

Keywords: caulerpine; spasmolytic effect; adrenergic receptors; guinea pig ileum. 


\section{Experimental}

\section{Caulerpine Isolation}

The isolation was performed as previously described (Cavalcante-Silva et al. 2013). Caulerpa sertularioides and C. mexicana algae were collected from the coastal region of Cabo Branco, João Pessoa, Paraíba State, Brazil in March 2009. The specimens were identified by Dr. George Emmanuel Cavalcanti de Miranda. Voucher specimens of $C$. sertularioides (JPB 13983) and C. mexicana (JPB 13985) have been deposited in the Lauro Pires Xavier Herbarium at the Federal University of Paraíba, Brazil. The algae were extracted with $\mathrm{MeOH}$ at room temperature and the extract was partitioned between hexane, dichloromethane, ethyl acetate and methanol. In the ethyl acetate phase there was precipitation of an orange-red pigment. On the basis of its NMR spectral data and chemical properties, it was assigned the structure of 5,12-dihydro-cycloocta [1,2- $b ; 5,6$ $b^{\prime}$ ]diindole-6,13-dicarboxylic acid dimethyl ester, named caulerpine or caulerpin. The caulerpine showed $99.4 \%$ purity in HPLC analysis as previously described (Cavalcante-Silva et al. 2014).

\section{Solutions and Drugs}

Caulerpine was dissolved in Cremophor ${ }^{\circledR}$ and diluted in distilled water. Carbamoylcholine chloride (carbachol - $\mathrm{CCh}$ ), cesium chloride $(\mathrm{CsCl})$, yohimbine hydrochloride and propranolol hydrochloride were purchased from Sigma-Aldrich (St. Louis, MO, USA) and were dissolved and diluted in distilled water. The physiological solution was a freshly modified Krebs solution ( $\mathrm{pH}$ 7.4) with the following composition (mM): $\mathrm{NaCl}$ (117.0), $\mathrm{KCl}$ (4.7), $\mathrm{MgSO}_{4}$ (1.3), $\mathrm{NaH}_{2} \mathrm{PO} 4$ (1.2), $\mathrm{CaCl}_{2}$ (2.5), glucose (11.0) and $\mathrm{NaHCO}_{3}$ (25.0). These salts were obtained from Vetec (Rio de Janeiro, RJ, Brazil) and Fmaia (Cotia, SP, Brazil).

\section{Animals}

Adult guinea pigs (Cavia porcellus) of both sexes from the Professor Thomas George Bioterium of CBiotec/UFPB, weighing $368 \pm 8 \mathrm{~g}$, were used. The animals had free access to food and water and were kept in rooms at $21 \pm 1{ }^{\circ} \mathrm{C}$ with a 12-h light-dark cycle, and they were fasted for $18 \mathrm{~h}$ before the experiments. Measures were taken to reduce pain, stress and any suffering, in accordance with the ethical guidelines for animal use. All experimental procedures were previously approved and performed in accordance with the guidelines of the Research Ethics Committee of the Federal University of Alagoas (UFAL) (protocol CEUA 039/2012).

\section{Measurement of Contraction of Guinea Pig Ileum}

Animals were euthanized by cervical dislocation and bled. The distal ileum was immediately removed, cleaned of adhering fat and connective tissue, immersed in modified Krebs solution at room temperature and continuously gassed with carbogen $\left(95 \% \mathrm{O}_{2}\right.$ and $\left.5 \% \mathrm{CO}_{2}\right)$. Segments of the ileum $(2-3 \mathrm{~cm}$ in length) oriented along the longitudinal muscle axis or circular muscle axis were suspended in a $5-\mathrm{mL}$ organ bath containing modified Krebs solution and maintained under resting load of $1.0 \mathrm{~g}$ at $37^{\circ} \mathrm{C}$. An isometric transducer (FORT10) coupled to an amplifier (TMB4M), both from World Precision Instruments (USA) was connected to an analog/digital converter board (Bio Data, Brazil) installed in a computer with BioMed ${ }^{\odot}$ software version RV2 and used to record isometric contractions.

\section{Pharmacological Experiments}

\section{Effect of the Caulerpine on CCh-Induced Phasic Contractions in Circular Muscle Layer}

After a stabilization period (120 min), two phasic contractions were obtained by $10^{-6} \mathrm{M} \mathrm{CCh}$ with intervals of 15 min between them. Caulerpine was then added, and after an incubation period of 15 min, a third 
concentration-response curve was obtained in the presence of $10^{-4}$ and $3 \times 10^{-4} \mathrm{M}$ caulerpine in different preparations.

\section{Effect of Caulerpine on CCh-induced Tonic Contractions in the Absence and Presence of Non-selective Potassium Channel Blocker $(\mathrm{Cs} C l)$}

After a stabilization period (30 min), an isometric contraction was elicited by $10^{-5} \mathrm{M} \mathrm{CCh}$. Contractile agents remained in contact with the preparation until a contraction plateau was reached (approximately $10 \mathrm{~min}$ ). Caulerpine was added cumulatively $\left(10^{-7}\right.$ up to $\left.10^{-3} \mathrm{M}\right)$ at the plateau phase, to obtain a relaxation curve (control). Afterwards, preparations were washed out and $5 \mathrm{mM} \mathrm{CsCl}$ (Cecchi et al. 1987), a non-selective potassium channel blocker, was added to the preparations for exposure of $20 \mathrm{~min}$. Other tonic contractions were then elicited in the presence of the blocker, and caulerpine was cumulatively added. Relaxation was expressed as percent reversal of initial contraction elicited by the contractile agents. The molar concentration of a substance that produces $50 \%$ of its maximal effect $\left(\mathrm{EC}_{50}\right)$ was obtained graphically from the concentrationresponse curves (Neubig et al. 2003). The relaxant potency of caulerpine was evaluated by comparing $\mathrm{EC}_{50}$ values in the absence and presence of the blocker.

\section{Effect of Caulerpine on CCh-induced Tonic Contractions in the Absence and Presence of Adrenergic Antagonists}

CCh-induced isometric contractions were obtained as described above. Afterwards, preparations were washed out and $1.3 \mu \mathrm{M}$ yohimbine, an antagonist of $\alpha_{2}$ adrenergic receptors (Fagbemi \& Salako 1982), or $5 \mu \mathrm{M}$ propranolol, an antagonist of $\beta$ adrenergic receptors (Bauer 1982), was added in different preparations for exposure of $20 \mathrm{~min}$. Other tonic contractions were elicited in the presence of the antagonists, and caulerpine was cumulatively added. Relaxation was expressed as percent reversal of initial contraction elicited by the contractile agents. The relaxant potency of caulerpine was evaluated by comparing $\mathrm{EC}_{50}$ values in the absence and presence of the antagonists.

\section{Statistical Analysis}

Data are expressed as means and S.E.M. EC $_{50}$ values were determined by nonlinear regression (Neubig et al. 2003). Differences between means were statistically compared using a $t$-test or one-way ANOVA followed by Bonferroni's test when appropriate. The significance level considered in all tests was $p<0.05$. All values were obtained using Graph-Pad Prism ${ }^{\circledR} 5.01$ software (GraphPad Software Inc., San Diego, CA, USA). 


\section{Supplementary Figure}

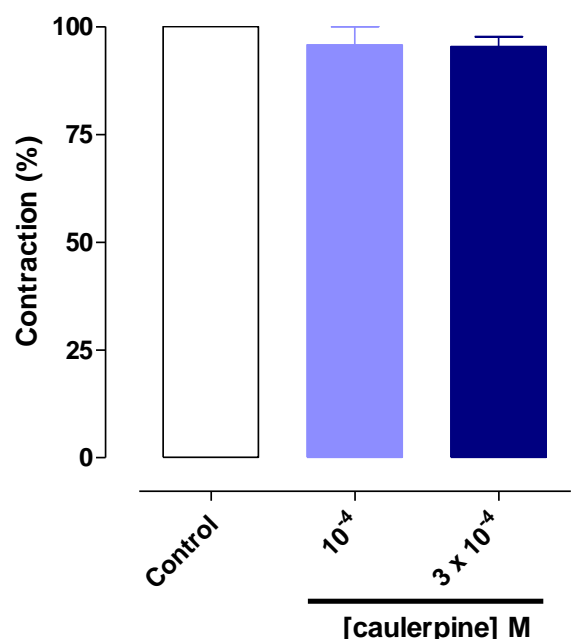

Figure S1. Effect of caulerpine on phasic contractions induced by $10^{-6} \mathrm{M} \mathrm{CCh}$ in circular muscle layer of guinea pig ileum $(n=3)$. Columns and vertical bars represent the means \pm S.E.M., respectively.
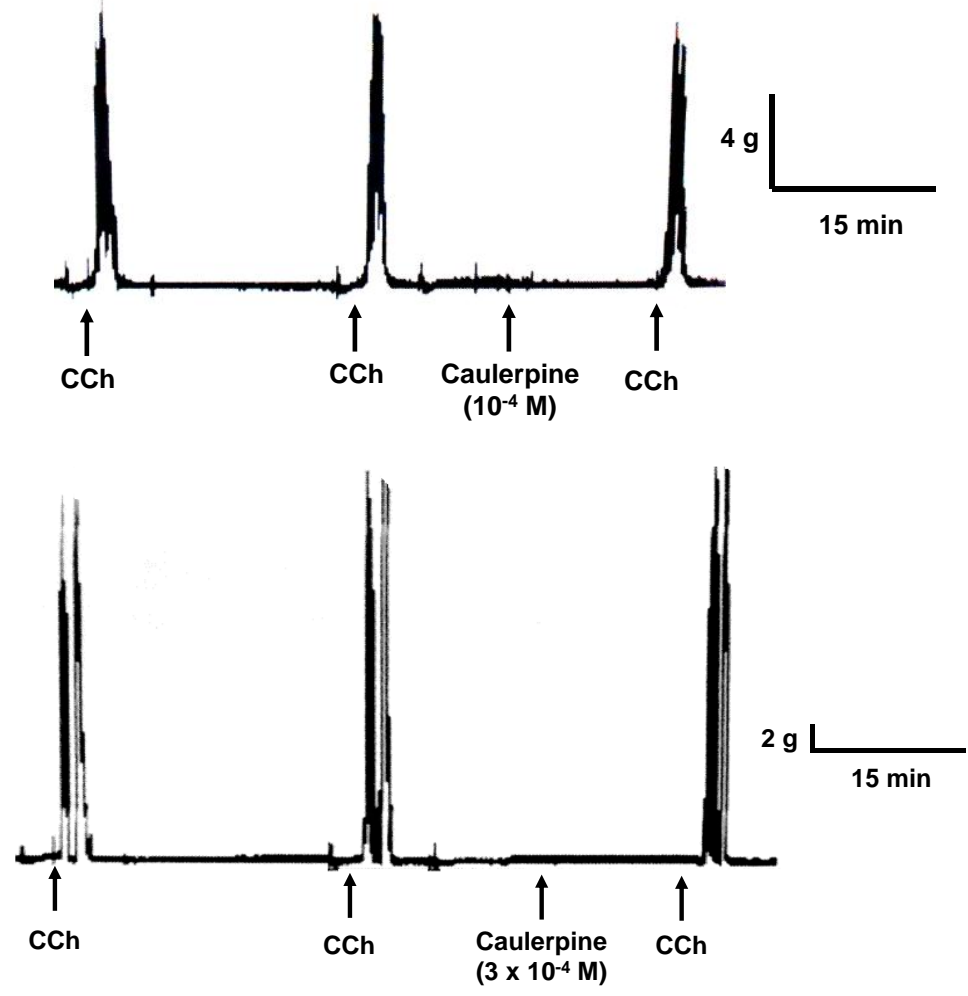

Figure S2. Representative trace of caulerpine effect on circular muscle layer of guinea pig ileum. 

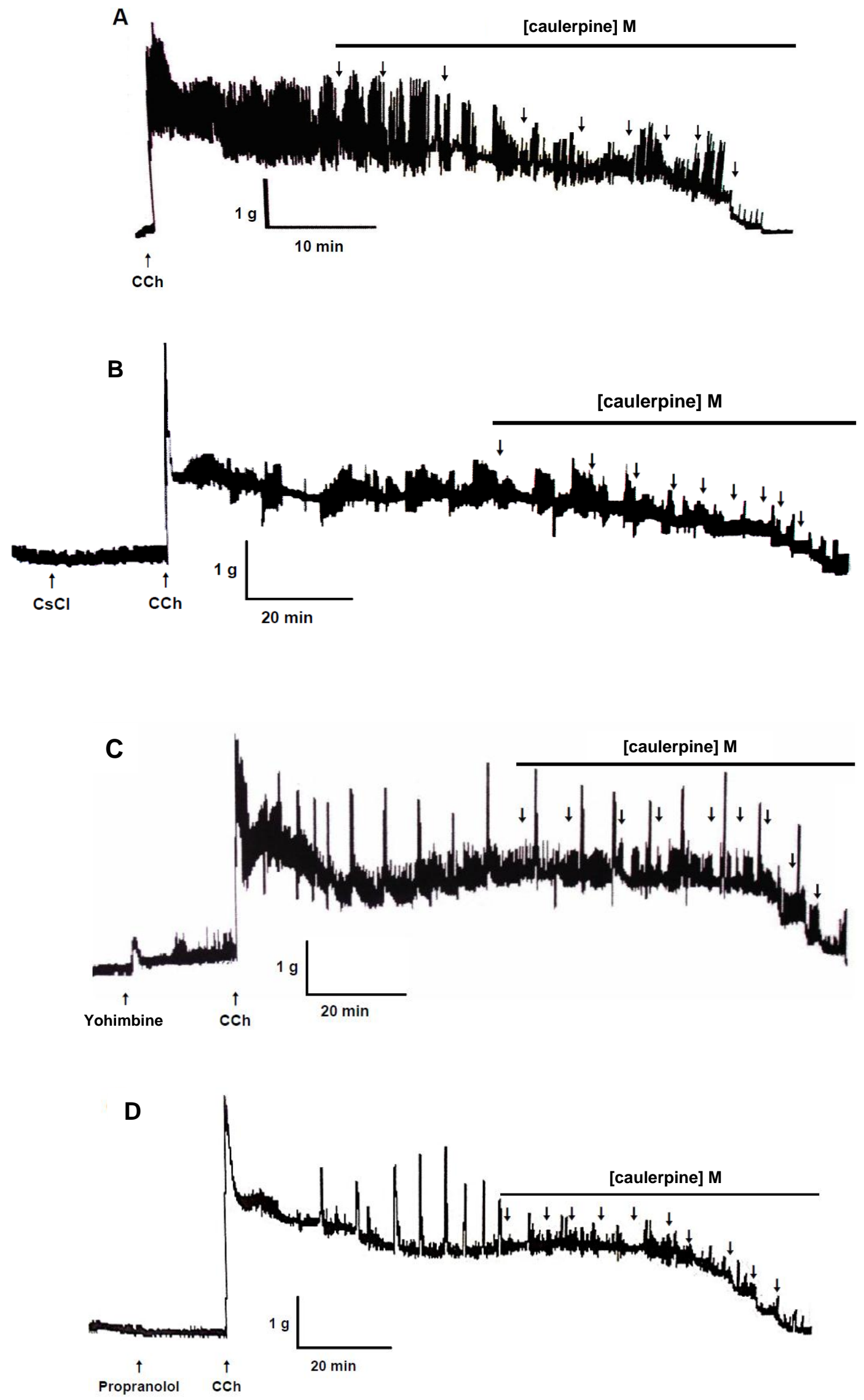

Figure S3. Representative trace of relaxant effect of caulerpine on tonic contractions induced by $10^{-5} \mathrm{M} \mathrm{CCh}$ in absence (A), and presence of 1,3 $\mu \mathrm{M}$ yohimbine (B) or $5 \mu \mathrm{M}$ propranolol (C) on guinea pig ileum. 
${ }^{1}$ Chung et al. 2001.

\begin{tabular}{c|c|c}
\hline & \multicolumn{2}{|c}{ EC $_{\mathbf{5 0}} \pm$ S.E.M $(\mathbf{M})$} \\
\hline & Caulerpine & Standard Drug \\
\hline Control & $4.7 \pm 0.7 \times 10^{-5}$ & -- \\
\hline $\mathrm{CsCl}(5 \mathrm{mM})$ & $3.0 \pm 0.7 \times 10^{-5}$ & -- \\
\hline Yohimbine $(1.3 \mu \mathrm{M})$ & $5.7 \pm 0.7 \times 10^{-5}$ & $6.2 \pm 0.2 \times 10^{-5} \mathrm{M}$ (clonidine) $^{1}$ \\
\hline Propranolol $(5 \mu \mathrm{M})$ & $2.2 \pm 0.2 \times 10^{-4 * * *}$ & $2.1 \times 10^{-8} \mathrm{M}$ (isoprenaline $^{2}$ \\
\hline
\end{tabular}

${ }^{2}$ Broadley KJ, Grassby, 1985.

Table S1. $\mathrm{EC}_{50}$ values of cumulatively-applied caulerpine on tonic contractions induced by $10^{-5} \mathrm{M}$ CCh in the absence and presence of different drugs on guinea pig ileum. ${ }^{* *} p<0.001$ (propranolol $v s$ control).

\section{References}

Bauer V. 1982. Distribution and types of adrenoceptors in the guinea-pig ileum: the action of $\alpha$-and $\beta$ adrenoceptor blocking agents. Br. J. Pharmacol. 76:569-578.

Broadley KJ, Grassby PF. 1985. Alpha- and beta-adrenoceptor-mediated responses of the guinea-pig ileum and the effects of neuronal uptake inhibition. Naunyn Schmiedebergs Arch Pharmacol. 331:316-323.

Cavalcante-Silva LHA, Correia ACC, Barbosa-Filho JM, Silva BA, Oliveira Santos BV, Lira DP, Sousa JCF, Miranda GEC, Cavalcante FA, Alexandre-Moreira MS. 2013. Spasmolytic effect of caulerpine involves blockade of $\mathrm{Ca}^{2+}$ influx on guinea pig ileum. Mar. Drugs. 11:1553-1564.

Cavalcante-Silva LHA, Falcão MAP, Vieira ACS, Viana MDM, Araújo-Júnior JX, Sousa JCF, Silva TMS, Barbosa-Filho JM, Noël F, Miranda GEC, et al. 2014. Assessment of mechanisms involved in antinociception produced by the alkaloid caulerpine. Molecules. 19:14699-14709.

Cecchi X, Wolff D, Alvarez O, Latorre R. 1987. Mechanisms of $\mathrm{Cs}^{+}$blockade in a $\mathrm{Ca}^{2+}$-activated $\mathrm{K}^{+}$channel from smooth muscle. Biophys. J. 52:707-716.

Chung S, Kwon S, Kim Y, Ahn D, Lee Y, Nam T. 2001. Inhibition by clonidine of the carbachol-induced tension development and nonselective cationic current in guinea pig ileal myocytes. Jpn J Pharmacol. 87:125-133.

Fagbemi SO, Salako LA. 1982. The effects of prazosin, phentolamine and phenoxybenzamine on inhibitory alpha-adrenoceptors in the guniea-pig isolated ileum. Br. J. Pharmacol. 76:235-243.

Neubig RR, Spedding M, Kenakin T, Christopoulos A. 2003. International Union of Pharmacology Committee on Receptor Nomenclature and Drug Classification. XXXVIII. Update on terms and symbols in quantitative pharmacology. Pharmacol. Rev. 55:597-606. 